\title{
BIOMIMÉTICA E REPRESENTAÇÃO GRÁFICA: ABORDAGEM INTEGRADA AO PROCESSO PROJETUAL EM ARQUITETURA
}

\author{
${ }^{1}$ Universidade Federal de Pelotas \\ ${ }^{2}$ Universidade Federal de Pelotas
}

Brunna Pereira de Oliveira ${ }^{1}$; Janice de Freitas Pires ${ }^{2}$.

\begin{abstract}
PALAVRAS CHAVE
Biomimética; Representação gráfica; Ação projetual; Modelagem paramétrica; Geometria complexa.
\end{abstract}

\section{KEY WORDS}

Biomimetics; Graphic representation; Project action; Parametric modeling; Complex geometry.

\section{RESUMO}

Este artigo está vinculado ao um projeto de pesquisa que trata da construção de referenciais didáticos para a adoção de técnicas de modelagem paramétrica e fabricação digital de superfícies complexas da arquitetura, por meio do estudo sobre o emprego de tais geometrias na prática profissional. Nesse contexto, identifica-se a abordagem da Biomimética como potencializadora à exploração de tais geometrias complexas na arquitetura. Tendo-se esta ciência como base, identificam-se as suas relações com a metodologia projetual, soluções arquitetônicas, os conceitos de arquitetura Tectônica e Estereotômica e a representação gráfica, a partir da leitura de artigos e fontes bibliográficas. A sistematização das relações reconhecidas visa subsidiar um processo de revisão acerca da potencialidade da estruturação desses saberes à ação projetual. Dessa maneira, o estudo configura-se como uma primeira abordagem de pesquisa com intuito de avançar na proposição e aplicação de atividades que promovam momentos didáticos de investigação das geometrias complexas da arquitetura, em especial as da natureza, e a sua representação por modelagem paramétrica e fabricação digital, o que auxiliará os acadêmicos de Arquitetura e Urbanismo a se apropriarem dessas novas soluções e abordagens contemporâneas de design.

\section{ABSTRACT}

This article is linked to a research project that deals with the construction of didactic references for the adoption of parametric modeling techniques and digital fabrication of complex architectural surfaces, through the study of the use of such geometries in professional practice. In this context, the Biomimetics approach is identified as a potential for the exploration of such complex geometries in architecture. Having this science as a base, its relations with the design methodology, architectural solutions, the concepts of tectonic and stereotomy architecture and the graphical representation are identified, from the reading of articles and bibliographical sources. The systematization of recognized 
relationships aims to support a review process about the potentiality of structuring this knowledge to design action. In this way, the study is configured as a first research approach in order to advance the proposition and application of activities that promote didactic moments of investigation of the complex geometries of architecture, especially those of nature, and their representation by parametric and digital fabrication, which will help architecture and urbanism scholars to appropriate these new contemporary design solutions and approaches. 


\section{INTRODUÇÃO}

Nas últimas cinco décadas, principalmente devido ao crescimento dos problemas ambientais que causam uma profunda preocupação em toda humanidade, o conceito de sustentabilidade passou a ser amplamente empregado na arquitetura. Aguirre et al (2008) chamam a atenção para eventos de catástrofes ambientais que causaram uma conscientização da importância de se agir para evitar a morte do planeta. Os autores destacam que a construção civil, os veículos motorizados e o uso das edificações consomem mais da metade dos recursos não renováveis e geram cerca da metade dos resíduos e emissões de $\mathrm{CO} 2$. Nesse contexto, entendem que os arquitetos e todos os agentes com poder de decisão que intervêm no processo de construção tornam-se corresponsáveis pelos graves problemas ambientais atuais. Dessa maneira, entendem que todo o indivíduo que habita o planeta deve ter consciência sobre sua responsabilidade para a manutenção da vida na Terra e considerar pequenas atitudes com este propósito. Nesse sentido, cabe aos técnicos a responsabilidade de propor soluções que venham a atender aos princípios da sustentabilidade, ou seja, "atendendo às necessidades do presente, sem comprometer o atendimento às necessidades das gerações futuras" (BRUNDTLAND, 1987, p. 16).

Houve um período da história da arquitetura em que a tecnologia de sistemas prediais teve impulso pela crença de que ofereceria meios para o controle total das condições ambientais de qualquer edifício, em detrimento ao uso da arquitetura bioclimática (GONÇALVES e DUARTE, 2006), baseada em mecanismos naturais de controle do conforto ambiental e consumo de energia. Isso, segundo as autoras, levou à prática de repetição das caixas de vidro e ao inerente exacerbado consumo de energia nas décadas seguintes, espalhando-se por cidades de todo o mundo. A "arquitetura bioclimática" retoma sua importância quando

\section{¿Unisul}

do surgimento do conceito de sustentabilidade, principalmente pelo fato de haver uma estreita relação entre o conforto ambiental e o consumo de energia, que ainda é enfrentado com o uso de sistemas de condicionamento ambiental e de iluminação artificiais, não considerando premissas próprias do meio natural.

Gonçalves e Duarte (2006, p. 53) destacam que embora o fato de as considerações sobre a energia consumida nos sistemas de climatização e iluminação artificial terem sido tão influentes na revisão das premissas arquitetônicas, já há mais de três décadas, não significa que outras investigações e propostas não estivessem sendo feitas. As autoras reiteram que paralelamente vinham sendo investigadas outras tecnologias para a sustentabilidade ambiental da arquitetura, incluindo também materiais e técnicas construtivas. E que, a partir das preocupações com o consumo de energia, originadas na década de 1970, o tema da arquitetura sustentável evoluiu para outros aspectos do impacto ambiental da construção, como o gerado pelos processos de industrialização dos materiais e a busca por sistemas prediais mais eficientes.

Uma abordagem que tem sido explorada na pesquisa e na prática de arquitetura é o conceito de biomimética, que tem relações profundas com o funcionamento do mundo natural e pode assim oferecer mecanismos e soluções para o projeto de artefatos artificiais.

É possível explorar formas arquitetônicas que incorporem características e atributos próprios do mundo natural, imitando o desempenho destas. Para tanto, o estudo da geometria e representação de tais formas pode ser um meio de exploração de soluções mais sustentáveis nos projetos de artefatos artificiais, como são os edifícios.

A complexidade de tais formas atualmente é estudada em um processo interdisciplinar, utilizando técnicas digitais de representação gráfica, tal como a modelagem paramétrica 
(WOODBURRY, 2010). Tais técnicas fornecem um espaço dinâmico de soluções de projeto, que podem integrar premissas do funcionamento e desempenho dos organismos do meio natural. Dessa maneira, além do conhecimento específico da geometria que constitui tais formas, as tecnologias digitais passam a ter um papel central em projetos de estruturas arquitetônicas sustentáveis.

Torna-se necessário inserir tais saberes no ensino de arquitetura, unindo os campos de conhecimento que abarcam os temas: geometria, técnicas digitais de representação e arquitetura sustentável,

O presente trabalho se insere no Projeto de Pesquisa AMPARA (Análise, Modelagem PARAmétrica e Fabricação Digital da geometria complexa da arquitetura: construção de referenciais didáticos para o ensino de projeto), da Faculdade de Arquitetura e Urbanismo da Universidade Federal de Pelotas, RS, que tem como objetivo a promoção não apenas de uma investigação acerca do emprego de superfícies complexas da arquitetura, como também de construções de referenciais didáticos para a adoção de técnicas de representação gráfica digital (modelagem paramétrica) e fabricação digital de tais superfícies como suporte à ação projetual. A Biomimética surge então como uma ciência com grande potencial à exploração na arquitetura de tais geometrias complexas, por meio da análise do funcionamento e do processo de geração da forma, próprios dos fenômenos naturais.

Esta ciência, também denominada de Biônica, consiste em analisar os sistemas naturais com o objetivo de identificar os princípios de soluções da natureza que, quando adaptados, auxiliam na resolução de problemas técnicos. Nesse contexto, a Biomimética permite a criação de analogias não somente com formas e funções, mas também com comportamentos e metodologias projetuais (FORCELLINI, 2002). Desse modo e de acordo com BERTOL (2011), “As ciências naturais têm um papel importante em ajudarnos a compreender a lógica do mundo natural e oferecem muitas lições para o desenho de formas artificiais" (BERTOL, 2011, p. IV). Ademais, é um campo que vem ganhando importância, crescendo na arquitetura e modificando os métodos de projetar. Segundo a autora, isso se deve a funcionalidade encontrada nas formas da natureza, pois oferecem não apenas uma inspiração estética, mas, principalmente, estratégias de projeto e eficiência estrutural, uma tendência que leva a uma abordagem interdisciplinar em projeto (BERTOL, 2011). Nessa direção, é possível traçar uma relação da teoria da evolução pela seleção natural, de Charles Darwin, que acontece na natureza, com a metodologia projetual, o que a faz ser uma abordagem importante no suporte à realização de projetos arquitetônicos.

Além disso, de acordo com SANTOS (2010), a Biomimética, quando agregada à representação gráfica, torna-se uma representante não apenas de suporte, como também de análise à ação projetual. Isso ocorre porque o desenho de observação permite uma maior atenção e consequente compreensão da estrutura dos objetos e, de acordo com BAHAMÓN (2006), “[...] la observación de la naturaleza y la experimentación han sido métodos de enorme utilidad para el diseño de formas arquitectónicas.". Acrescido a isso, o surgimento do desenho paramétrico na Arquitetura, que exige a extração e definição sistemática dos parâmetros e princípios que compõem os elementos arquitetônicos (HERNANDEZ, 2006), tem auxiliado na concepção das formas mais complexas, em particular as recorrentes na natureza, o que proporciona rapidez e fluidez do desenho e, consequentemente, do projeto.

Nos estágios iniciais do ensino de arquitetura da Faculdade de Arquitetura e Urbanismo (FAUrb), contexto no qual este 
trabalho se insere -, as formas complexas definidas por meio de superfícies curvas fazem parte do vocabulário de projeto dos estudantes, sem haver, no entanto, uma explicitação e reconhecimento prévios dos tipos de geometrias que estão envolvidas em tais formas e nem de sua representação no ateliê. Como consequência disso, os estudantes acabam optando em seus projetos por formas simples ou tentam propor curvas complexas sem consciência dos conceitos geométricos e atributos arquitetônicos, técnicos e tecnológicos das geometrias que foram empregadas. No ateliê de projeto do segundo semestre do curso, ocorre a introdução dos conceitos de arquitetura Tectônica e Estereotômica a partir de BAEZA (2003) para aquisição da consciência construtiva da arquitetura e, posteriormente, a exploração de superfícies curvas enfatizando as abóbadas. No entanto, entende-se que tais conceitos devam ser introduzidos em conjunto para ganharem mais significado e compreensão e pergunta-se de que maneiras a Biomimética pode contribuir e potencializar essa compreensão. Além disso, nota-se a necessidade de realizar atividades que promovam o reconhecimento dos elementos geométricos fundamentais curvas, processos de geração e técnicas de representação - dos mais variados tipos de abóbadas.

Considerando a importância da coordenação entre tais conceitos, este trabalho busca investigar as relações existentes entre o comportamento da natureza, a metodologia projetual, soluções arquitetônicas, os conceitos de Tectônica e Estereotômica - abordados no ateliê de projeto - e a representação gráfica para subsidiar um processo de revisão e análise acerca da potencialidade da estruturação desses saberes à ação projetual e futura proposição e aplicação de atividades didáticas.

\section{REFERENCIAL TEÓRICO}

O termo Biomimética - Biomimicry, em inglês - vem do grego bios (vida) e mimesis (imitação) e surgiu na década de 1970 pelo casal John Todd e Nancy Jack-Todd, inseridos no grupo The New Alchemy Institute. De acordo com eles, essa ciência tem por objetivo compreender a natureza a partir do estudo da ecologia, da biologia e de sistemas biocibernéticos para realizar uma associação harmônica entre o artificial e o natural e possibilitar a investigação de soluções mais sustentáveis às necessidades humanas. Nesse mesmo sentido, BENYUS (2003) descreve as abordagens presentes na Biomimética:

\section{a. A natureza como modelo. A biomimética é uma nova ciência que estuda os modelos da natureza e depois imita-os ou inspira-se neles ou em seus processos para resolver os problemas humanos [...]. \\ b. A natureza como medida. A biomimética usa um padrão ecológico para ajuizar a "correção" das nossas inovações. Após 3,8 bilhões de anos de evolução, a natureza aprendeu: $\mathrm{O}$ que funciona. O que é apropriado. O que dura. \\ c. A natureza como mentora. A biomimética é uma nova forma de ver e valorizar a natureza. Ela inaugura uma era cujas bases se assentam não naquilo que podemos extrair da natureza, mas no que podemos aprender com ela (BENYUS, 2003).}

Ainda segundo esse autor, a Biomimética permite uma compreensão complexa do ecossistema e uma consequente promoção da adaptação do homem ao meio - e não o oposto -, de forma a obedecer a ordem natural das coisas. Nesse contexto, BENYUS (2003) também afirma que um mundo onde a indústria e a produção funcionassem a partir da replicação dos processos de animais e plantas teria como resultado uma existência totalmente biodegradável. Dessa maneira, é possível observar a importância dessa ciência para lidar com a atual crise ecológica global e para proteger e garantir a qualidade de vida na Terra. Ademais, para além da sustentabilidade, 
LITTMANN (2009) aponta a necessidade de a arquitetura ampliar a relação com o meio ambiente a partir da compreensão completa dos sistemas naturais para projetar estruturas regenerativas. Nesse sentido, para este autor, a análise do local com o objetivo de identificar padrões possui um papel central no desenvolvimento de um projeto regenerativo, isso porque, segundo o autor, as estruturas naturais se desenvolvem em torno de um fluxo de energia e integram princípios regenerativos. Á vista disso, percebe-se a importância de considerar tais estruturas e o estudo da Biomimética como referenciais na arquitetura.

Além disso, os projetos arquitetônicos que possuem sua metodologia e forma inspiradas na natureza estão estruturados em saberes que fundamentam questões de desempenho na arquitetura, a partir do conceito de otimização. Embora esta abordagem já tenha permeado a arquitetura no passado, especialmente nas obras de arquitetos como Gaudí, Frei Otto e Felix Candela, nos últimos 20 anos, as formas inspiradas na natureza são vistas cada vez mais como requisitos projetuais em obras arquitetônicas (POTTMANN et al, 2007). Isso ocorre porque, de acordo com PEREZGARCIA e GÓMEZ-MARTÍNEZ (2009), a natureza desenvolve as suas estruturas com o objetivo de sempre atingir soluções energéticas ideais em longos prazos. Desse modo, a Biomimética mostra-se com grande potencial para explicitar e aplicar conceitos da geometria complexa na arquitetura que possuem integração funcional e eficiência estrutural. BERTOL (2011) apresenta exemplos desse tipo de associação entre a natureza e a arquitetura a partir da relação existente entre a geodésica proposta por Buckminster Fuller e as radiolárias - protozoários planctônicos de vida marinha - por ambas possuírem uma estrutura com a forma fundamental para $o$ equilíbrio recorrente nos organismos da natureza, isto é, com um padrão triangular, conforme pode ser observado na Figura 1.
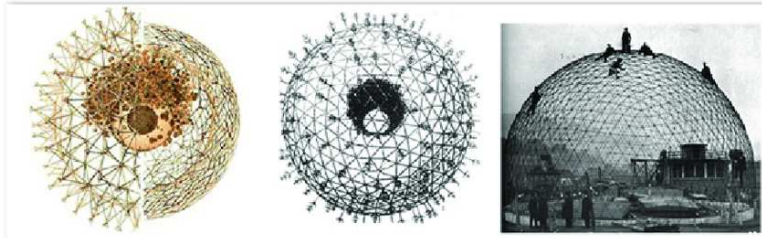

Figura 1: Radiolária desenhada por E. Hackel (1872) à esquerda e ao centro e forma geodésica do Planetário em Jena (C. Zeiss) à direita.

\section{Fonte: PEREZ-GARCIA e GÓMEZ- MARTÍNEZ (2009)}

Quanto a abordagem para desenvolver projetos com o uso da Biomimética, sua pesquisa pode ser realizada, segundo BARBOSA (2008), de duas maneiras:

[...], projetos em biônica podem ser desenvolvidos de duas formas: top down, onde o problema define a pesquisa, e botton up, onde a observação de uma determinada forma, método ou processo existente na natureza é transformado em um banco de dados que pode ser usado para gerar um produto potencial (BARBOSA, 2008).

Tendo isso em vista, os projetos de arquitetura tendem a ser top down, pois, de acordo com LÖBACH (2000), o processo de design não é apenas um processo criativo, como também um processo de solução de problemas. Nessa direção, o autor descreve a metodologia projetual como reunir, analisar e relacionar todas as informações sobre $\mathrm{o}$ problema de forma a causar um processo de diversas ideias, a fim de criar alternativas para solucioná-lo e, posteriormente, julgar as soluções encontradas e, em conformidade com critérios, selecionar a mais adaptada a eles para desenvolver. Acrescido a isso, pode-se relacionar o método de projeto com a metodologia da natureza - a maneira com que ela se desenvolve e evolui.

Em 1850, o naturalista, geólogo e biólogo Charles Darwin (1809 - 1882) escreveu o livro "A Origem das Espécies" onde sugere e relata que as espécies podem mudar ao longo do tempo e que essa evolução (descendência com 
modificação) acontece a partir de um mecanismo de seleção natural. Nessa perspectiva, os seres que apresentarem características favoráveis - decorrentes de uma variação genética - às mudanças ambientais irão sobreviver por causa dessas características e, ao se reproduzirem, irão evoluir e tornar as espécies mais adaptadas aos seus ambientes ao longo do tempo. Dessa maneira e partindo do princípio de que o "design é o processo de adaptação do ambiente 'artificial' às necessidades físicas e psíquicas dos homens na sociedade." (LÖBACH, 2000, p.14), é possível comparar a teoria da evolução pela seleção natural de Darwin com a metodologia projetual.

No que se refere à representação gráfica, SANTOS (2010) afirma que o desenho faz parte de todas as etapas do desenvolvimento de um projeto e que desde o início do pensamento projetual, no século XIII, as diferentes formas de representação $o$ amparam pela sua capacidade de externalizar as ideias projetuais. Além disso, com o avanço da técnica e o auxílio de ferramentas computacionais, novas formas de representar tem revolucionado o processo de projetar. A representação e modelagem paramétrica, que consiste num modelo digital descrito através de parâmetros e relações entre os seus elementos geométricos, possibilita uma grande variedade de soluções alternativas à proposição ou conformação final de um objeto arquitetônico (WOODBURY, 2010). Outrossim, a natureza descritiva da modelagem paramétrica pode auxiliar na concepção de formas mais complexas e potencializar a explicitação do saber da geometria complexa das estruturas presentes na natureza. À vista disso, nota-se que a representação paramétrica possui grande potencial de auxílio à ação projetual, mesmo que exija, ao contrário do processo tradicional de projeto, um pensamento botton up, em que os dados e requisitos do projeto são associados em cadeia, conjuntamente com a definição da geometria e dos elementos construtivos.
Os conceitos de arquitetura Tectônica e Estereotômica, abordados no ateliê de projeto em estágios iniciais da formação em arquitetura, são fundamentados em BAEZA (2003). Esse autor destaca as diferenças entre as duas abordagens, na primeira, a estrutura é descontínua, mas leve, como a da cabana, necessitando de artifícios para controle de luz, já que esta passa por seus pilares, treliças e vigas. Já a arquitetura Estereotômica é a arquitetura da caverna, isto é, maciça, pétrea e pesada, com um sistema estrutural contínuo e que necessita da perfuração de suas superfícies para que a luz entre, como por exemplo abóbadas e paredes portantes. Diante disso, pode-se afirmar que são conceitos opostos e complementares e que conforme LEGAULT (2005) possuem grande importância no ensino de arquitetura e podem proporcionar avanços a partir de sua aplicação:

Os ganhos teóricos e conceituais advindos da
reflexão sobre a tectônica são consideráveis. Em
primeiro lugar, o discurso sobre a tectônica irá
permitir ultrapassar a dicotomia convencional e o
reducionismo entre construção e arquitetura, uma
prevenção para o tratamento dessas questões de
maneira separada. Em segundo lugar, o discurso
permitirá apreender a arquitetura em sua
dimensão material e construtiva, encorajando o
desenvolvimento de um olhar concreto sobre o
objeto construído. Em terceiro lugar, esse
discurso permitirá renovar a atenção sobre a ideia
de arquitetura como métier e sobre a prática da
arquitetura como arte da fabricação.
(LEGAULT, 2005, p.39).

A partir de tais referenciais, tenta-se compreender de que maneiras o estudo da Biomimética e da representação gráfica digital pode se integrar as abordagens apresentadas aos estudantes de arquitetura no atelier de projeto e como essa ciência se relaciona com a metodologia projetual, soluções arquitetônicas e de que forma a estruturação desses saberes pode auxiliar na ação projetual, já que, segundo BAHAMÓN (2006) "[...] no existe mejor laboratório experimental que uma evolución de siglos, ni mejor garante de eficacia que la adaptabilidad de ciertas formas 
naturales a su entorno".

\section{METODOLOGIA}

O trabalho trata-se de um processo de revisão bibliográfica que fora desenvolvido a partir da leitura de artigos e fontes bibliográficas sobre as relações existentes entre a Biomimética, a Arquitetura, o processo projetual, os conceitos de arquitetura Tectônica e Estereotômica, a representação gráfica e a abordagem paramétrica de projeto e de representação. Após isso, foi realizada a sistematização dessas relações por meio de tabelas, com base nos estudos de BAEZA (2003), LOBACH (2000), REBELLO (2000) e SANTOS (2010), que auxiliaram para uma comparação direta e melhor explicitação dos referenciais estudados/pesquisados.

Incialmente efetuou-se uma relação entre o comportamento evolutivo da natureza pela seleção natural de Charles Darwin e o método de projeto, conforme as fases de LOBACH (2000). Após isso, associaram-se os estudos de casos apresentados em SANTOS (2010) e REBELLO (2000), em que a Biomimética atuou como percursora de soluções arquitetônicas e, posteriormente, realizou-se uma estruturação acerca dos conceitos de Tectônica e Estereotômica, a partir de BAEZA (2003), visando compreender seus princípios. Dessa maneira, relacionaram-se tais conceitos com os estudos de casos anteriormente sistematizados e por fim, fez-se uma análise sobre os tipos de representações aplicadas a cada fase da metodologia projetual analisada. Como conclusão do estudo, tenta-se compreender as conexões entre cada abordagem e apontar de que maneira essas associações podem contribuir em atividades de atelier.

\section{RESULTADOS E DISCUSSÃO}

A revisão desenvolvida já permitiu traçar uma análise acerca da metodologia projetual e a sua relação com o funcionamento da natureza e com a representação gráfica, de estudos de caso em que a Biomimética atuou como pioneira de soluções arquitetônicas, dos conceitos de arquitetura Tectônica e Estereotômica abordados no segundo semestre da (omitido para a avaliação as cegas) e sistematizar esses resultados visando compreender a sua contribuição ao projeto de pesquisa (omitido para a avaliação as cegas).

Como já referido anteriormente, existem analogias entre o comportamento evolutivo da natureza pela seleção natural de Charles Darwin e o método de projeto. Nesse contexto, assim como o meio muda - problema - e causa um processo aleatório de diversidade para que os seres vivos, ao se reproduzirem, evoluírem e adaptarem-se a ele, os projetos arquitetônicos possuem um programa de necessidades a ser atendido, interesses e um local de implantação - problema - que causam um processo pensado de diversidades de ideias para que alguma dessas soluções esteja de acordo com os requisitos de projeto e, assim, haver a sua materialização. Sendo assim, foi realizada a sistematização desses processos com a categorização deles baseada na divisão do trabalho projetual em quatro fases de LOBACH (2000), apresentadas em SANTOS (2010), conforme na Tabela 01.

Tabela 01: Sistematização da relação entre a evolução da natureza pela seleção natural e o método de projeto. Fonte: Elaborado pelos autores a partir de Santos (2010).

\begin{tabular}{|c|c|c|}
\hline Fase & $\begin{array}{c}\text { Comportamento } \\
\text { da Natureza }\end{array}$ & $\begin{array}{c}\text { Metodologia } \\
\text { projetual }\end{array}$ \\
\hline $\begin{array}{l}\text { Análise do } \\
\text { problema. }\end{array}$ & $\begin{array}{lr}\text { Somatório dos } \\
\text { fatores ambientais } \\
\text { existentes ou }\end{array}$ & $\begin{array}{l}\text { Conhecimento } \\
\text { do problema, } \\
\text { das }\end{array}$ \\
\hline
\end{tabular}




\begin{tabular}{|c|c|c|}
\hline & $\begin{array}{l}\text { futuros } \\
\text { imprevisíveis - que } \\
\text { se relacionarão } \\
\text { com o organismo. }\end{array}$ & $\begin{array}{l}\text { necessidades e } \\
\text { interesses. }\end{array}$ \\
\hline $\begin{array}{l}\text { Geração das } \\
\text { alternativas } \\
\text { para } \\
\text { solução do } \\
\text { problema }\end{array}$ & $\begin{array}{l}\text { Processo aleatório } \\
\text { de produção de } \\
\text { diversidade }- \text { não é } \\
\text { direcionado à } \\
\text { resolução dos } \\
\text { problemas. }\end{array}$ & $\begin{array}{l}\text { Livre } \\
\text { associação de } \\
\text { ideias com alto } \\
\text { grau } \\
\text { liberdade } \\
\text { incerteza. }\end{array}$ \\
\hline $\begin{array}{l}\text { Avaliação } \\
\text { das } \\
\text { alternativas } \\
\text { para } \\
\text { solução do } \\
\text { problema }\end{array}$ & $\begin{array}{l}\text { Quando as forças } \\
\text { selecionadoras da } \\
\text { natureza agem. }\end{array}$ & $\begin{array}{l}\text { As possíveis } \\
\text { soluções } \\
\text { encontradas são } \\
\text { confrontadas } \\
\text { com os } \\
\text { requisitos de } \\
\text { projeto. }\end{array}$ \\
\hline $\begin{array}{l}\text { Realização } \\
\text { da solução } \\
\text { do } \\
\text { problema }\end{array}$ & $\begin{array}{lr}\text { Processo } & \text { de } \\
\text { reprodução } & \text { dos } \\
\text { organismos. } & \end{array}$ & $\begin{array}{l}\text { Materialização } \\
\text { da ideia em } \\
\text { produto. }\end{array}$ \\
\hline
\end{tabular}

Após, foi elaborada uma relação entre os estudos de casos apresentados em SANTOS (2010) e REBELLO (2000), em que a Biomimética atuou como percursora de soluções arquitetônicas e que podem ir das mais simples às mais complexas (Tabela 02).

Tabela 02: Sistematização de estudos de caso. Fonte: Elaborado pelos autores a partir de Santos (2010) e Rebello (2000).

\begin{tabular}{|c|c|c|}
\hline Natureza & $\begin{array}{l}\text { Projeto } \\
\text { arquitetônico }\end{array}$ & Explicação (função) \\
\hline axis & 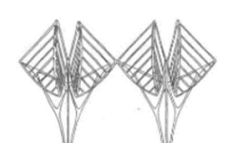 & \multirow{2}{*}{$\begin{array}{l}\text { Os galhos dessas } \\
\text { árvores aumentam de } \\
\text { seção da sua } \\
\text { extremidade ao tronco } \\
\text { de acordo com a } \\
\text { intensificação } \\
\text { esforços }- \text { maiores } \\
\text { quanto mais próximos } \\
\text { do tronco }- \text { e na } \\
\text { cobertura de Calatrava } \\
\text { cada pilar comporta-se } \\
\text { como um galho, } \\
\text { obtendo uma solução } \\
\text { mais econômica. }\end{array}$} \\
\hline $\begin{array}{l}\text { Galhos de } \\
\text { árvores } \\
\text { frondosas. }\end{array}$ & $\begin{array}{l}\text { Cobertura de } \\
\text { Santiago } \\
\text { Calatrava. }\end{array}$ & \\
\hline
\end{tabular}

\begin{tabular}{|c|c|c|}
\hline $\begin{array}{l}\text { Asa } \\
\text { libélula }\end{array}$ & $\begin{array}{l}\text { Hall of Labor - } \\
\text { Nervi }\end{array}$ & $\begin{array}{l}\text { Conceito de estrutura } \\
\text { como caminho de } \\
\text { forças: as nervuras das } \\
\text { asas das libélulas vão } \\
\text { aumentando de } \\
\text { espessura conforme se } \\
\text { aproximam do tronco, } \\
\text { nesse sentido, as barras } \\
\text { estruturais - nervuras - } \\
\text { do edifício convergem } \\
\text { para as vigas - tronco - } \\
\text { que se apoiam sobre os } \\
\text { pilares. }\end{array}$ \\
\hline $\begin{array}{l}\text { Casa do } \\
\text { de Barro }\end{array}$ & $\begin{array}{l}\text { Pantheon } \\
\text { Adriano }\end{array}$ & $\begin{array}{l}\text { A casa do João de Barro } \\
\text { é feita de fibras vegetais } \\
\text { e barro e tem a forma de } \\
\text { uma cúpula com } \\
\text { esforço de compressão } \\
\text { simples e o Pantheon } \\
\text { foi feito de alvenaria, } \\
\text { argamassa de cal e } \\
\text { pozolana com boa } \\
\text { resistência à } \\
\text { compressão. Ambas as } \\
\text { formas em cúpula são } \\
\text { adequadas ao tipo de } \\
\text { material disponível. }\end{array}$ \\
\hline $\begin{array}{l}\text { Concha } \\
\text { marinha }\end{array}$ & $\begin{array}{l}\text { Restaurante } \\
\text { Los } \\
\text { Manantiales, } \\
\text { Cidade do } \\
\text { México - Félix } \\
\text { Candela }\end{array}$ & $\begin{array}{l}\text { As nervuras das } \\
\text { conchas aumentam a } \\
\text { rigidez delas e evitam } \\
\text { que elas deformem a } \\
\text { partir de esforços de } \\
\text { compressão. } \\
\text { estrutura pode ser vista } \\
\text { na cobertura do } \\
\text { restaurante de Candela } \\
\text { e ela pode vencer um } \\
\text { vão de } 30 \mathrm{~m} \text { com } \\
\text { apenas } 10 \mathrm{~cm} \text { de } \\
\text { espessura. }\end{array}$ \\
\hline
\end{tabular}

A partir de tais autores, foi possível compreender que a Biomimética pode ser utilizada não apenas como um suporte de base ao método de projeto, como também de obtenção de soluções arquitetônicas. Posteriormente, para analisar de que maneira a estruturação desses saberes pode contribuir e ser aplicado no ateliê de projeto, foi feita uma estruturação acerca dos conceitos de Tectônica e Estereotômica, a partir de BAEZA (2003), conforme a Tabela 03.

Tabela 03: Conceitos de Tectônica e Estereotômica. Fonte: Elaborado pelos autores a partir de Baeza (2003). 

AMBIENTAL

\section{¿unisul E}

\begin{tabular}{|c|c|}
\hline Tectônica & Estereotômica \\
\hline Cabana & Caverna \\
\hline $\begin{array}{l}\text { Madeira, bambu, cana; } \\
\text { aço }\end{array}$ & $\begin{array}{l}\text { Tijolo, pedra, adobe e } \\
\text { concreto armado }\end{array}$ \\
\hline $\begin{array}{l}\text { Imaterialidade } \quad \text { da } \\
\text { concepção }\end{array}$ & Materialidade da massa \\
\hline $\begin{array}{l}\text { Sistema estrutural com } \\
\text { nós }\end{array}$ & $\begin{array}{l}\text { Sistema estrutural } \\
\text { contínuo }\end{array}$ \\
\hline $\begin{array}{l}\text { Gravidade se transmite } \\
\text { de forma acentuada }\end{array}$ & $\begin{array}{l}\text { Gravidade se transmite } \\
\text { de forma contínua }\end{array}$ \\
\hline Construção articulada & Construção contínua \\
\hline $\begin{array}{l}\text { Arquitetura } \\
\text { lenhosa, leve }\end{array}$ & $\begin{array}{l}\text { Arquitetura maciça, } \\
\text { pétrea, pesada }\end{array}$ \\
\hline $\begin{array}{l}\text { Pousa na terra como em } \\
\text { bicos de pés }\end{array}$ & $\begin{array}{l}\text { Assenta na terra como se } \\
\text { dela nascesse }\end{array}$ \\
\hline $\begin{array}{l}\text { Tapa-se os locais com } \\
\text { paredes para controlar a } \\
\text { luz que entra (defende-se } \\
\text { da luz) }\end{array}$ & $\begin{array}{l}\text { Perfuram-se as paredes } \\
\text { para a entrada de luz no } \\
\text { seu interior (busca luz) }\end{array}$ \\
\hline $\begin{array}{l}\text { Esforços de tração } \\
\text { (momentos) }\end{array}$ & Esforços de compressão \\
\hline $\begin{array}{lcc}\text { Sistema } & \text { de vigas } & \text { e } \\
\text { pilares, } & \text { tesouras } & \mathrm{e} \\
\text { treliças } & & \\
\end{array}$ & $\begin{array}{l}\text { Paredes } \\
\text { abóbadas }\end{array}$ \\
\hline
\end{tabular}

A partir desta caracterização, foi possível traçar uma análise da relação entre os conceitos de Arquitetura Tectônica e Estereotômica e os estudos de casos sistematizados anteriormente, conforme a sistematização apresentada na Tabela 04.

Tabela 04: Análise da relação entre os conceitos de Arquitetura Tectônica e Estereotômica e os estudos de casos. Fonte: Elaborado pelos autores.

\begin{tabular}{|c|c|}
\hline $\begin{array}{l}\text { Estudo de } \\
\text { Caso }\end{array}$ & $\begin{array}{l}\text { Aplicação dos termos Tectônica } \\
\text { e Estereotômica }\end{array}$ \\
\hline $\begin{array}{c}\text { Galhos de } \\
\text { árvores } \\
\text { frondosas. }\end{array}$ & $\begin{array}{l}\text { Arquitetura Tectônica } \\
\text { construção articulada } \rightarrow \text { vários } \\
\text { elementos articulados entre si }\end{array}$ \\
& $\begin{array}{l}\text { - Arquitetura óssea, lenhosa, leve } \\
\text { de pés } \rightarrow \text { um único ponto de contato } \\
\text { com o solo }\end{array}$ \\
\hline
\end{tabular}

\begin{tabular}{|c|c|}
\hline $\begin{array}{c}\text { Cobertura de } \\
\text { Santiago } \\
\text { Calatrava }\end{array}$ & $\begin{array}{l}\text { - Gravidade se transmite de } \\
\text { forma acentuada } \\
\text { O controle da luz se dá através da adição } \\
\text { de elementos; "tapar" } \rightarrow \text { as folhagens da } \\
\text { árvore controlam a luz e fazem sombra } \\
\text { enquanto paredes independentes fariam } \\
\text { isso na cobertura }\end{array}$ \\
\hline $\begin{array}{l}\text { Hall of Labor } \\
\text { - Nervi }\end{array}$ & $\begin{array}{l}\text { Arquitetura Tectônica } \\
\text { - Sistema estrutural com nós, } \\
\text { construção articulada } \rightarrow \text { elementos } \\
\text { articulados entre si com muitos nós } \\
\text { - Sistema de vigas e pilares, } \\
\text { tesouras e treliças } \\
\text { - Esforços de tração (momentos) } \\
\text { - Pousa na terra como em bicos } \\
\text { de pés } \rightarrow \text { pontos de contato com o } \\
\text { solo } \\
\text { - Gravidade se transmite de } \\
\text { forma acentuada } \\
\text { O controle da luz se dá através da adição } \\
\text { de elementos } \rightarrow \text { "tapar" }\end{array}$ \\
\hline $\begin{array}{c}\text { Pantheon - } \\
\text { Adriano }\end{array}$ & $\begin{array}{l}\text { Arquitetura Estereotômica } \\
\text { - Sistema estrutural contínuo e a } \\
\text { gravidade se transmite de forma } \\
\text { contínua } \rightarrow \text { é possível observar a } \\
\text { continuidade presente } \\
\text { - Arquitetura maciça, pétrea, } \\
\text { pesada } \rightarrow \text { materialidade da massa } \\
\text { - Assenta na terra como se dela } \\
\text { nascesse } \\
\text { - O controle da luz se dá através } \\
\text { da subtração de elementos } \rightarrow \\
\text { "perfurar" } \\
\text { - Esforços de compressão } \\
\text { Paredes portantes, abóbadas } \rightarrow \text { formato } \\
\text { de cúpula visível. }\end{array}$ \\
\hline $\begin{array}{l}\text { Restaurante } \\
\text { Los } \\
\text { Manantiales, }\end{array}$ & $\begin{array}{l}\text { Arquitetura Estereotômica } \\
\text { - Sistema estrutural contínuo e a } \\
\text { gravidade se transmite de forma } \\
\text { contínua } \rightarrow \text { é possível observar a } \\
\text { continuidade presente na concha } \\
\text { - Arquitetura maciça, pétrea, } \\
\text { pesada } \rightarrow \text { materialidade da massa } \\
\text { - O controle da luz se dá através } \\
\text { da subtração de elementos } \rightarrow \\
\text { "perfurar" } \\
\text { - Esforços de compressão }\end{array}$ \\
\hline
\end{tabular}




\begin{tabular}{|c|l|}
\hline Cidade do & Paredes portantes, abóbadas $\rightarrow$ formato \\
México - & de abóbada visível tanto na Concha \\
Félix Candela & Marinha como no Restaurante. \\
\hline
\end{tabular}

Com isso, pôde-se afirmar que o conhecimento, a observação e a associação da/à natureza também permitem um auxílio no entendimento e aplicação dos termos de arquitetura Tectônica e Estereotômica e, consequentemente, no desenvolvimento da consciência construtiva de maneira mais didática no ateliê de projeto.

Quanto à representação gráfica, foi traçada uma análise para relacionar que tipo de desenho é utilizado para cada fase da metodologia projetual analisada, conforme a Tabela 05, com o objetivo de observar as potencialidades de cada representação à ação projetual.

Tabela 05: Análise das potencialidades da representação gráfica em cada etapa projetual. Fonte: Elaborado pelos autores a partir de Santos (2010).

\begin{tabular}{|c|c|}
\hline Fase & $\begin{array}{l}\text { Representação gráfica (tipos } \\
\text { e função) }\end{array}$ \\
\hline $\begin{array}{l}\text { Análise do } \\
\text { problema. }\end{array}$ & $\begin{array}{l}\text { Desenho analítico/de observação. } \\
\text { Permite o reconhecimento de aspectos } \\
\text { gerais e particulares do problema. }\end{array}$ \\
\hline $\begin{array}{l}\text { Geração das } \\
\text { alternativas } \\
\text { para solução do } \\
\text { problema }\end{array}$ & $\begin{array}{l}\text { Desenho criativo. } \\
\quad \begin{array}{l}\text { Permite a exploração da } \\
\text { forma. }\end{array} \\
\begin{array}{l}\text { Desenhos livres, } \\
\text { geométricos, } \\
\text { representações } \\
\text { digitais. }\end{array}\end{array}$ \\
\hline $\begin{array}{l}\text { Avaliação das } \\
\text { alternativas } \\
\text { para solução do } \\
\text { problema }\end{array}$ & $\begin{array}{l}\text { Desenho como suporte ao raciocínio } \\
\text { de extensão da memória. } \\
\text { - Permite que exista um ciclo } \\
\text { de operações simultâneas. } \\
\text { Aspectos funcionais, espaciais, } \\
\text { formais, materiais, construtivos, } \\
\text { dinâmicos, de equilíbrio etc. Desenho } \\
\text { paramétrico para avaliação e seleção } \\
\text { de soluções. }\end{array}$ \\
\hline
\end{tabular}

\begin{tabular}{|c|c|}
\hline $\begin{array}{ll}\text { Realização } & \text { da } \\
\text { solução } & \text { do } \\
\text { problema } & \end{array}$ & $\begin{array}{l}\text { Desenho como ferramenta de } \\
\text { comunicação de ideias e precisão da } \\
\text { fabricação. } \\
\text { - Permite comunicar a ideia } \\
\text { do projeto com precisão para a } \\
\text { construção. }\end{array}$ \\
\hline & $\begin{array}{l}\text { Desenvolvimento de modelos } \mathrm{e} \\
\text { protótipos, fabricação. }\end{array}$ \\
\hline
\end{tabular}

Dessa forma, a partir dessa sistematização, observou-se que o desenho analítico é um forte aliado na compreensão da natureza e, consequentemente, das suas estruturas. Ademais, a parametrização do projeto a partir da representação paramétrica, além de exigir tal processo de análise, é um expoente de otimização ao permitir não apenas a comunicação de todas as fases projetuais - a exploração da forma, um ciclo de operações simultâneas, a comunicação das ideias e a precisão para a construção do projeto - como também a modelagem de formas e estruturas complexas que são encontradas na natureza.

\section{CONCLUSÕES}

Conforme destaca Silva et al (2013), fica evidente a necessidade de uma crescente busca de soluções mais criativas, inovadoras e ecologicamente compromissadas que poderão regular a transformação das nossas cidades para o futuro. E isso só será possível com uma ampla e profunda formação profissional embasada em tais ideais, adotando-se uma clara visão do papel que as tecnologias digitais terão neste processo.

Littman (2009) declara que um edifício "verde" se concentra tradicionalmente apenas na primeira parte de uma arquitetura sustentável e regenerativa. Ela emprega a tecnologia como meio de redução e conservação. Nesse sentido, o autor compreende que o método de concepção e construção de estruturas desprovidas de processos naturais e compromisso mínimo com o meio ambiente é ainda não natural e 
ilógico. Para o autor, compreender o funcionamento do meio natural é uma das premissas da arquitetura regenerativa. Segundo ele, o mundo natural é uma coleção de muitos sistemas naturais e os fluxos de energia que estão integralmente ligados. Cada sistema individual depende de todos os outros sistemas para a operação saudável. A teia de interconectividade e relações mutuamente benéficas que existem no nosso mundo é, para Littman (2009, p. 17-18), literalmente o fundamento pelo qual existimos.

$\mathrm{O}$ presente trabalho explicitou os saberes acerca da Biomimética como uma alternativa para soluções arquitetônicas em conjunto com a representação paramétrica no processo de projeto, que se configuram não apenas como um recurso ao método de projeto, mas também como subsídios importantes à ação projetual e formativa, voltada a abordagens contemporâneas de design. Isso auxiliará os acadêmicos de Arquitetura e Urbanismo a se atualizarem e apropriarem-se de novos saberes, métodos e soluções que vem sendo produzidos e a obterem uma maior compreensão sobre o funcionamento estrutural de seus projetos.

Nesse sentido, este trabalho irá permitir avançar na proposição e aplicação de atividades que promovam momentos didáticos de investigação das geometrias complexas da arquitetura e sua representação por modelagem paramétrica e fabricação digital, no projeto em questão. Isso se deve à associação das estruturas de saber identificadas para uma compreensão da relação da geometria da natureza com o processo projetual e a sua representação.

Como continuidade da pesquisa, serão propostas atividades de modelagem paramétrica de geometrias complexas da natureza, inspiradas nas potencialidades da Biomimética e dos conceitos de Tectônica e Estereotômica, a partir dos estudos de caso reunidos na pesquisa. Estas atividades serão estruturadas para que se relacionem com cada fase de projeto (análise do problema, geração de alternativas para solução e avaliação).

\section{REFERÊNCIAS}

AGUIRRE, Lina de Moraes; OLIVEIRA, Juliano; BRITTO CORREA, Celina. Habitando o container. Living Inside the Container. In: $7^{\circ}$ Seminário Internacional do Núcleo de Pesquisa em Tecnologia da Arquitetura e Urbanismo (NUTAU) da Universidade de São Paulo - Espaço Sustentável: Inovações em edifícios e cidades, $2008 . \quad$ Disponível em: http://www.usp.br/nutau/CD/69.pdf. Acesso em: janeiro de 2021.

BAEZA, Alberto Campo. De la cueva a la cabaña. Sobre lo estereotómico y lo tectónico em arquitectura. Sustancia y circunstancia: memoria del curso 2002-2003 de las asignaturas proyectos arquitectónicos 4 e 5 . Madrid: Mairea Libros, 2003.

BAHAMÓN, Alejandro.; PÉREZ, Patricia.; CAMPELLO, Alex. Arquitectura vegetal: analogias entre el mundo vegetal y la arquitectura contemporânea. $1^{\mathrm{a}}$ Edição. Barcelona: Parramón ediciones S.A., 2006.

BARBOSA, Enio Rodrigo. Inspiração que vem da natureza exige visão multidisciplinar na pesquisa. Cienc. Cult., São Paulo, v. 60, n. 3, 2008.

BENYUS, J. M. Biomimética: inovação inspirada pela natureza. São Paulo: editora Cultrix, 2003.

BERTOL, Daniela. FORM GEOMETRY STRUCTURE: from nature to design. $1^{\text {a }}$ Edição. Exton, Pennsylvania: Bentley Institute Press, 2011.

BRUNDTLAND, Gro Harlem. Our common future: The World Commission on Environment and Development. Oxford: Oxford University, 1987. 
FORCELLINI, F.A. Apostila de Projeto de Produto. [S.1.]: [s.n.], 2002.

GONÇALVES, Joana Carla Soares; DUARTE, Denise Helena Silva. Arquitetura sustentável: uma integração entre ambiente, projeto e tecnologia em experiências de pesquisa, prática e ensino. Sustainable architecture: integration among environment, design and technology in research, design practice and education. Ambiente Construído, Porto Alegre, v. 6, n. 4, p. 51-81 out./dez. 2006. ISSN 1415- 8876, Associação Nacional de Tecnologia do Ambiente Construído. Disponível em: https://seer.ufrgs.br/ambienteconstruido/articl e/view/3720. Acesso em: fevereiro de 2021.

HERNANDEZ, Carlos R. Barrios. Thinking parametric design: introducing parametric Gaudi. Design Studies. Cambridge: Elsevier Ltd, v. 27, n. 3, 2006, p. 309-324.

LEGAULT, R. La trajectoire tectonique. In: CHUPIN, J., SIMONETTE, C.(org). Le projet tectonique. Gollion: Infólio éditions, 2005.

LITTMAN, J. A. Regenerative Architecture: A Pathway Beyond Sustainability. Dissertação de Mestrado. University of Massachusetts Amherst. 2009. 68 p. Disponível em: http://scholarworks.umass.edu/cgi/viewconten t.cgi? article $=1389 \&$ context $=$ theses $\quad$ Acesso em: 06 fev. 2021.

LOBÄCH, B. Design industrial: bases para a configuração de produtos industriais. São Paulo: Edgard Blücher, 2000.

PEREZ-GARCIA, A.; GÓMEZ-MARTÍNEZ, F. Natural structures: strategies for geometric and morphological optimization. Proceedings of the International Association for Shell and Spatial Structures (IASS) Symposium 2009, Valencia Evolution and Trends in Design, Analysis and Construction of Shell and Spatial Structures 28 September - 2 October 2009, Universidad Politecnica de Valencia, Spain. Alberto DOMINGO and Carlos LAZARO (eds.).
POTTMANN, H. ASPERL, A. HOFER, M. KILIAN, A. Architectural Geometry. Exton, Pennsylvania: Bentley Institute Press, $1^{\mathrm{a}}$ ed., 2007.

REBELLO, Y.C.P. A Concepção Estrutural e a Arquitetura. $1^{\circ}$ Edição. São Paulo: Zigurate Editora, 2000.

SANTOS, Claudemilson dos. O DESENHO COMO PROCESSO DE APLICAÇÃO DA BIOMIMÉTICA NA ARQUITETURA E NO DESIGN. Revista Tópos. Presidente Prudente:UNESP, v. 4, n. 2, 2010, p. 144 192.

SILVA, Diego Fagundes da; COSTA E MATTOS, Erica Azevedo da; FAGUNDES, Thêmis da Cruz; KÓS, José Ripper. Prospecção Projetual para o Desenvolvimento de um Urbanismo Ecológico: Florianópolis e o Caso do Rio Vermelho. In: $6^{\circ}$ Projetar - O Projeto como Instrumento para a Materialização da Arquitetura: ensino, pesquisa e prática. Salvador, 26-29 novembro 2013.

WOODBURY, R. Elements of Parametric Design. London: Routledge, 2010.

\section{Agradecimentos}

Agradecemos ao Conselho Nacional de Pesquisa (CNPq) pela bolsa de iniciação científica (2020-21), a qual oportunizou desenvolver esta pesquisa. 